\title{
An eco-designed paper-based algal biosensor for nanoformulated herbicide optical detection
}

\author{
Viviana Scognamiglio $^{\mathrm{a}, *}$, Amina Antonacci ${ }^{\mathrm{a}}$, Fabiana Arduini ${ }^{\mathrm{b}}$, Danila Moscone ${ }^{\mathrm{b}}$, \\ Estefania V.R. Campos ${ }^{\mathrm{c}}$, Leonardo F. Fraceto ${ }^{\mathrm{c}}$, Giuseppe Palleschi ${ }^{\mathrm{b}}$ \\ ${ }^{a}$ Institute of Crystallography, National Research Council, Department of Chemical Sciences and Materials Technologies, Via Salaria Km 29.3, 00015, Monterotondo Scalo, \\ Rome, Italy \\ ${ }^{\mathrm{b}}$ Department of Chemical Science and Technologies, Università di Roma Tor Vergata, Via della Ricerca Scientifica, 00133, Rome, Italy \\ ${ }^{\mathrm{c}}$ São Paulo State University (UNESP), Institute of Science and Technology of Sorocaba, Laboratory of Environmental Nanotechnology, Av. Três de Março, 511 - CEP 18- \\ 087-180, Sorocaba, Brazil
}

\section{A R T I C L E I N F O}

\section{Keywords:}

Paper-based algal biosensor

Chlamydomonas reinhardtii

Chlorophyll fluorescence

Nanoencapsulated-atrazine

Sustainable agriculture

\begin{abstract}
A B S T R A C T
In this study we reported the development of a paper-based algal biosensor for the optical detection of nanoencapsulated-atrazine, a forefront nanoformulated herbicide with a high effective post-emergence herbicidal activity. In particular, the unicellular green photosynthetic algae Chlamydomonas reinhardtii was immobilised on a paper substrate soaked with an agar thin film and placed in a glass optical measurement cell, obtaining a totally environmental-friendly device. Nanoencapsulated-atrazine was detected by following the variable fluorescence $\left(1-\mathrm{V}_{\mathrm{J}}\right)$ parameter, which decreased inversely proportional to the herbicide concentrations, in a range between 0.5 and $200 \mathrm{nM}$, indicating a linear relationship in the measured dose-response curves and a detection limit of $4 \mathrm{pM}$. Interference studies resulted in a very slight interference in presence of $2 \mathrm{ppm}$ copper and $10 \mathrm{ppb}$ arsenic at safety limits, as well as a slight matrix effect and a satisfactory recovery value of $96 \pm 5 \%$ for $75 \mathrm{nM}$ nanoencapsulated-atrazine in tap water. Stability studies were also performed obtaining a good storage stability up to 3 weeks. Results demonstrated the suitability of the proposed paper-based optical biosensor as a valid support in smart agriculture for on site, environmental friendly, cost effective and sensitive nanoencapsulated-atrazine analysis.
\end{abstract}

\section{Introduction}

The increasing demographic pressure, climate change, and industrial globalization of last decades represent nowadays few main global challenges, being factors that generate a huge impact on the environment and people well-being. Among human actions, agriculture is one of the main cause of environmental pollution since farming activities have been oriented toward intensive agricultural practices. Indeed, there is the indiscriminate use of pesticides that contribute to soil and water pollution, with important consequences on different ecosystems. For this reason, most countries have established maximum residue levels (MRL) in food products to limit pesticide use and exposure to such dangerous compounds (European Union Legislation, http://europa.eu.int/eurlx/en/indx.html). Their accepted concentrations are $0.1 \mu \mathrm{g} / \mathrm{L}$ for each single pollutant and $0.5 \mu \mathrm{g} / \mathrm{L}$ for total pesticides (Drinking water Directive, Council Directive 98/83/EC).

As a consequence, consumer demand for more sustainable agricultural practices and waste minimisation has become imperative in modern agrifood sector. In this context, smart agriculture entails the exploitation of different multifarious approaches based on a more efficient energy and environmentally friendly cross-cutting technologies, including i) novel nanoformulations to increase the dispersion and wettability of agricultural pesticides/fertilisers and ii) advanced diagnostic tools for the analysis of ground/drinking water to assess water matrix pollution levels [1,2]. Nanoherbicides are gaining momentum in the last years as novel formulations for smart agriculture, being a more sustainable route for weed growth control with minimised release of toxic residues in soil and environment, owing to a smarter delivery system of the active ingredients [3,4]. In addition, some preliminary results indicated that the nanoformulation can impact on the fate of herbicides, which are usually undergo biotic or abiotic degradation [5].

Among different pesticides, atrazine represents a case study herbicide, being widely used for pre- and post-emergence control of weeds in agriculture and acting as an inhibitor of photosynthesis by specific

\footnotetext{
* Corresponding author.

E-mail address: viviana.scognamiglio@ic.cnr.it (V. Scognamiglio).
} 
binding to photosystem II. After soil treatment, this herbicide can reach surface or subsurface waters during irrigation or rain events, contributing to the pollution [6,7]. Moreover, the slow degradation of this herbicide under natural conditions results in high persistence in the environment and consequently in the contamination of soil, water resources, and food [8]. Recently many regulations have been defined also for atrazine, establishing a limits between 0.6 and $2 \mu \mathrm{g} / \mathrm{L}$ in surface water matrices (Directive 2013/39/EU) [9].

A more proficient use of atrazine can be achieved by the use of nanoscale carriers, which reduce the amount of herbicide to be applied but increasing its efficiency, with minimised impact on the environment. Recently, Oliveira and co-workers developed nanostructured carrier systems for atrazine as a promising strategy to minimize its contamination of natural resources [10]. In detail, the authors prepared nanocapsules of poly( $\varepsilon$-caprolactone) (PCL), a biodegradable aliphatic polyester nontoxic to humans and environment, and loaded them with atrazine to obtain a nanoencapsulated herbicide. This nanoencapsulated-atrazine (nanoatrazine) shows a huge potential as a forefront nanoformulation for applications in smart agriculture, being able to provide higher effective herbicidal activity and lower toxic impact on the environment.

However, as stated by Kah and co-workers, "the current level of knowledge does not appear to allow a fair assessment of the benefits and/or risks that will result from the use of some nanopesticides" [5]. Moreover, any reliable data evidenced that these novel formulations can be persistent in the different environmental compartments, thus generating detriment to water matrices of agrifood and human health interest. For this reason, effective biosensing systems to reveal the pollution level of different environments, as surface and drinking waters, caused by these novel nanoformulated herbicides are mandatory, with analytical features custom-shaped on the structure of these compounds. To date, some paper-based biosensors are reported in the literature based on different bioreceptors towards different toxic compounds [11-16]; conversely biosensors or bioassays have been not specifically designed for the detection of nanoformulated pesticides. In this scenario, we present for the first time the development of a biosensor to sense nanoherbicides for applications in smart agriculture.

In particular, we described a paper-based optical biosensor consisting of whole cells of the green photosynthetic algae Chlamydomonas reinhardtii immobilised on a paper substrate for the detection of nanoencapsulated-atrazine. Paper is gaining momentum in the design of biosensors for many application fields owing to its enormous advantages, compared to traditional 3D scaffolds made of inorganic materials, polymers, metals, and composite materials, in terms of cost-effectiveness, simple synthesis procedures, and environmental sustainability. In addition, the high porosity, flexibility, tunability, amenability to high-throughput analysis, biocompatibility and thus suitability of paper towards cell growth, make this substrate an old material performing forefront tricks $[17,18]$. Chlamydomonas reinhardtii algae was herein combined with paper as substrate for the first time thanks to its ability to reveal photosynthetic herbicides by means of a simple and effective mechanism. Indeed, variations of algal chlorophyll fluorescence emission occur in the presence of similar toxic compounds, due to a specific interaction between the photosynthetic herbicide and the plastoquinone $\mathrm{Q}_{\boldsymbol{B}}$ binding niche present in the $\mathrm{D} 1$ protein of the Photosystem II of the algae [19-23].

The rational to design a paper-based algal biosensor for the detection of nanoatrazine is to furnish a pioneering analytical tool for application in smart agriculture encompassing the fundamentals of sustainability of the recent sustainable agricultural practices. Indeed, the combination of a Generally Recognized as Safe (GRAS) organism, as Chlamydomonas is recognised by the FDA [24], with an environmentally-friendly material as paper opens novel directions towards the development of innovative biosensor concepts entailing the basic principles of sustainability of the intelligent farming. A similar biosensing configuration can be used as a disposable system for the optical monitoring of nanoencapsulated-atrazine and further wasted as biodegradable material without impacting on the environment.

\section{Experimental section}

\subsection{Chemicals}

Copper $\left(\mathrm{Cu}^{2+}\right)$ and arsenic (AsIII) were purchased from Carlo Erba. Tris-acetate-phosphate, poly( $\varepsilon$-caprolactone), Polysorbate 80 (Tween 80 ), acetone and sorbitane monostearate (Span 60) were purchased from Sigma (Aldrich Corporation, USA).

\subsection{PCL nanocapsules preparation}

PCL nanocapsules were prepared by the interfacial deposition of pre-formed polymer method [25]. This technique involves the mixing of an organic phase consisting of polymer, surfactant (Span 60), oil (Myritol 318), and the active compound (herbicide) into an aqueous phase containing Tween 80 . The nanocapsules formed were stored in amber flasks at a temperature of $25^{\circ} \mathrm{C}$. The technique of photon correlation spectroscopy and microelectrophoresis were used to determine the hydrodynamic diameter and zeta potential of the nanoparticles, respectively. The samples (nanocapsules and nanoatrazine) were diluted 100-fold with deionized water (Milli-Q) and analysed using a ZetaSizer ZS 90 (Malvern ${ }^{\oplus}$ ) at a fixed angle of $90^{\circ}$ and temperatures of $25^{\circ} \mathrm{C}$. In addition, the hydrodynamic diameter and nanoparticle concentration/mL were analysed using the Nanoparticle tracking analysis (NTA). For NTA, the samples were diluted 5000-fold and analysed in a volumetric cell using a NanoSight LM10 equipment (CMOS camera and NanoSight software - version 3.2). All measurements were performed in triplicate. The nanoparticle morphology was measured using the Easy Scan 2 Basic AFM instrument (Nanosurf, Switzerland). For the AFM analyses, the nanoparticles suspensions were diluted 500-fold and then dripped onto a silicon plate and left to dry for 7 days. In order to scan the samples, the instrument was operated in contact mode using a TapA1-G cantilevers (BudgetSensors, Bulgaria). The images were processed using the Gwyddion 2.45 software. The size distribution of the nanoparticles was measured using a total of 100 nanoparticles.

\subsection{C. reinhardtii IL strain and growth colture conditions}

For all the experiments an IL strain of $C$. reinhardtii was exploited, a mutant containing an intronless $p s b A$ gene encoding for the $\mathrm{D} 1$ protein of Photosystem II [26,27]. Algae cultures were photoheterotrophically grown in Tris-acetate-phosphate (TAP) medium pH 7.2 prepared according to Harris protocol [28], under continuous light at $50 \mu \mathrm{mol}$ photons $/ \mathrm{m}^{2} / \mathrm{s}$ (OSRAM Fluora) and with stirring at $150 \mathrm{rpm}$ at $25^{\circ} \mathrm{C}$ (Certomat BS-1 incubator, Sartorius).

\subsection{Measurement of colture growth, photosynthetic activity, and chlorophyll contents}

All experiments were performed exploiting cell cultures in early mid-exponential growth phase, with $\mathrm{Abs}_{750} \sim 0.5$ O.D., corresponding to $8 \pm 2 \times 10^{5}$ cells $/ \mathrm{mL}$, and $8 \mu \mathrm{g} / \mathrm{mL}$ chlorophyll content. Cell colture growth was evaluated spectrophotometrically by quantifying the absorbance (O.D.) at $750 \mathrm{~nm}$ wavelength. Cell number was assessed by a Bio-Rad TC-10 automated counter (Hemel Hempstead, UK). Pigment content was calculated by the Lichtenthaler method once extracted with $80 \%$ acetone [29].

The algae photosynthetic profile was estimated by recording the chlorophyll fluorescence induction curves (Kautsky curves) in the absence and in the presence of nanencapsulated atrazine by a Plant Efficiency Analyzer (PEA, Hansatech Instr. Ltd., Kings Lynn, Norfolk, $\mathrm{UK})$, at room temperature after $10 \mathrm{~min}$ of dark adaptation and with a $3 \mathrm{~s}$ saturating pulse excitation light $\left(600 \mathrm{~W} / \mathrm{m}^{2}\right)$ provided by an array of six 
$\mathbf{A}$

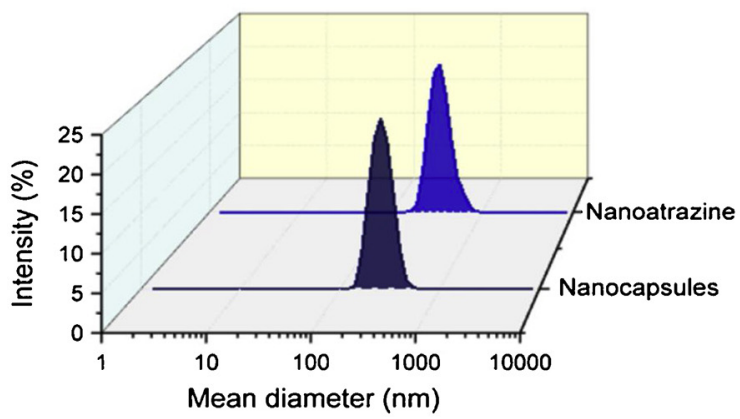

B

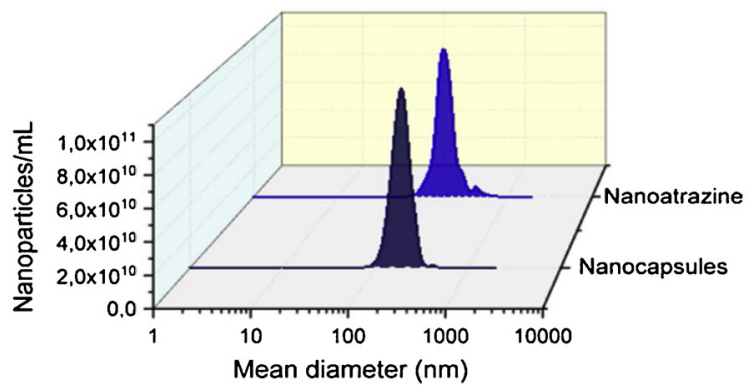

C

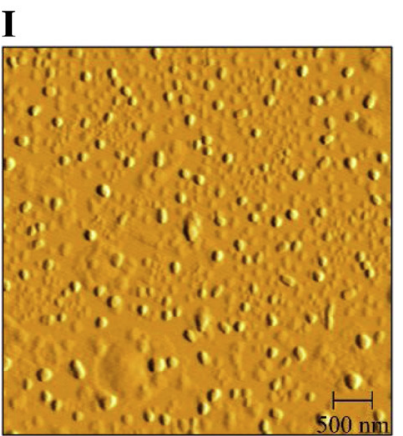

II

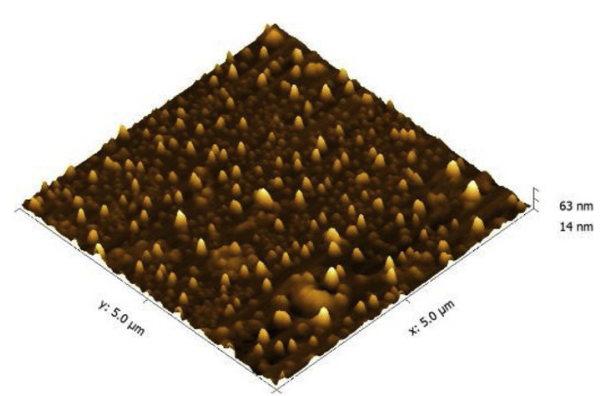

III

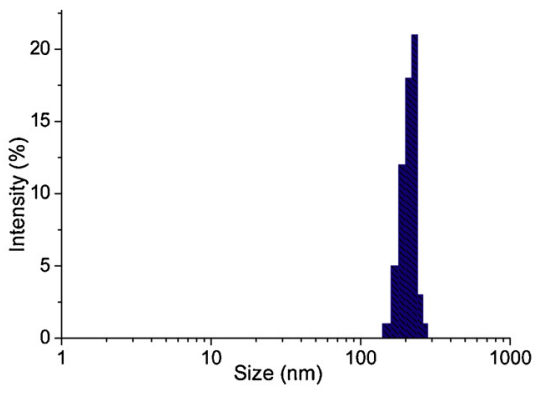

III

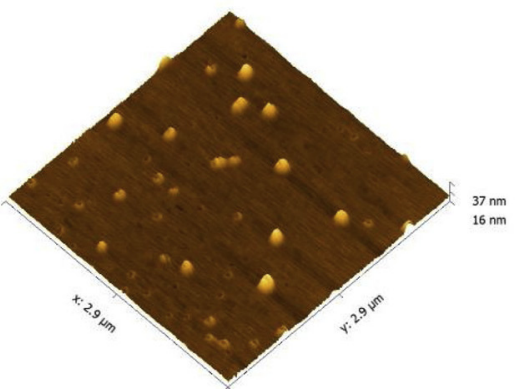

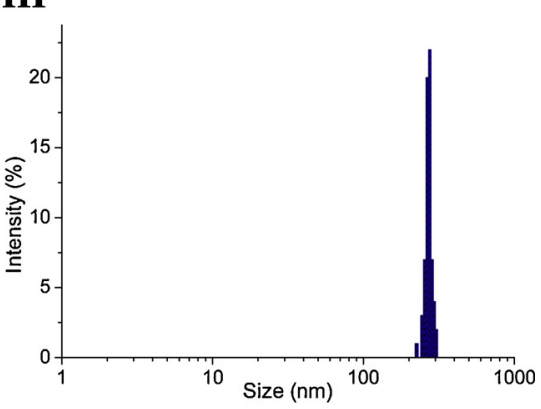

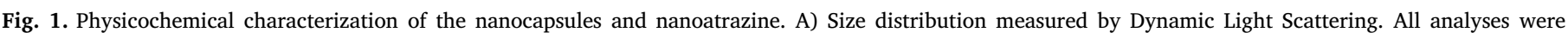

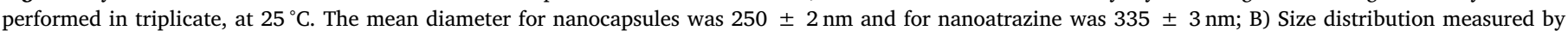

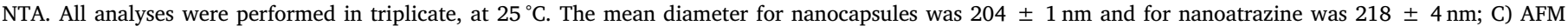

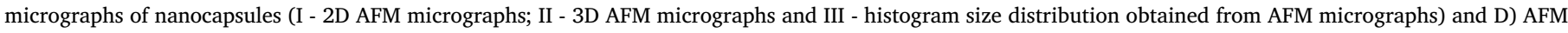

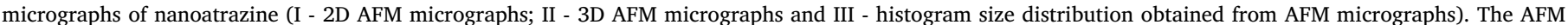

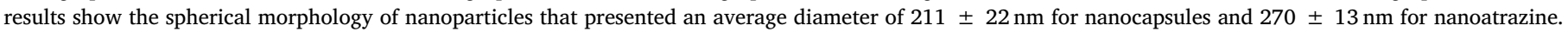

red light emitting diodes (650 nm peak). Kautsky curves are described by a polyphasic fluorescence rise in the time, called OJIP curves, where $O$ represents the minimal dark-adapted fluorescence level (where all $Q_{A}$ are oxidised) and $\mathrm{P}$ the maximal level (where all PSII quinone acceptors are fully reduced). Using the difference in the fluorescence signal between these two distinct states it is possible to evaluate PSII functionality via the parameter $\mathrm{F}_{\mathrm{V}} / \mathrm{F}_{\mathrm{M}}$, which represent the maximum fluorescence yield of PSII photochemical reaction and is calculated according to the Eq. (1):

$\mathrm{F}_{\mathrm{V}} / \mathrm{F}_{\mathrm{M}}=\left(\mathrm{F}_{\mathrm{M}}-\mathrm{F}_{0}\right) / \mathrm{F}_{\mathrm{M}}$

where $\mathrm{F}_{\mathrm{V}}$ represents the maximum variable fluorescence calculated as $\mathrm{F}_{\mathrm{M}}-\mathrm{F}_{0}, \mathrm{~F}_{\mathrm{M}}$ corresponds to the maximum fluorescence emission and $\mathrm{F}_{0}$ is the minimum fluorescence emission. $\mathrm{F}_{\mathrm{V}} / \mathrm{F}_{\mathrm{M}}$ values decrease in an analyte concentration dependent manner where the target analyte is able to impact on the integrity of the photosynthetic apparatus thus inhibiting photosynthetic reactions.

Moreover, the intermediate points $\mathrm{J}$ and $\mathrm{I}$ are a direct indication of transient changes in the plastoquinone redox state within the PSII reaction centre, as the accumulation of $\mathrm{Q}_{\mathrm{A}}$ in reduced state and the consequent filling up of the plastoquinone pool with electrons [19-22]. Any change in the PSII electron transfer efficiency directly causes variations in the fluorescence intensity of the inflection points, as a consequence of different stress conditions, as for example the presence of pollutants. In particular, the variable fluorescence parameter $1-\mathrm{V}_{\mathrm{J}}$ considers all the parameters involved in the fluorescence emission profile and provides a more specific response directly correlated to the herbicide-D1 binding niche interaction [23]. This parameter is calculated according to the Eq. (2):

$1-\mathrm{V}_{\mathrm{J}}=1-\left(\mathrm{F}_{2 \mathrm{~ms}}-\mathrm{F}_{0}\right) /\left(\mathrm{F}_{\mathrm{M}}-\mathrm{F}_{0}\right)$ 
where $F_{0}, F_{M}, F_{2 m s}$ are respectively the initial fluorescence, the maximum fluorescence and the fluorescence measured after $2 \mathrm{~ms}$.

\subsection{C. reinhardtii immobilisation and instrument set-up}

C. reinhardtii cell cultures in early mid-exponential growth phase, with $\mathrm{Abs}_{750} \sim 0.5$ O.D., corresponding to $8 \pm 2 \times 10^{5}$ cells $/ \mathrm{mL}$, and $8 \mu \mathrm{g} / \mathrm{mL}$ chlorophyll content, were exploited for the immobilisation on agar hydrogel/paper substrate. Approximately $4 \pm 0.5 \times 10^{6}$ cells were harvested by means of $5 \mathrm{~min}$ centrifugation at $2000 \times \mathrm{g}$ and $15^{\circ} \mathrm{C}$. The cell pellet was washed, re-suspended in Tris-acetate-phosphate (TAP) medium pH 7.2 to a final volume of $200 \mu \mathrm{L}$, and placed on a cellulose substrate (diameter $1 \mathrm{~cm}$ ) soaked into an $1.5 \%(\mathrm{w} / \mathrm{v})$ agar hydrogel made in Tris-acetate-phosphate (TAP) medium pH 7.2 to form a film. The paper substrate was then accommodated into the measurement cell of the PEA instrument for fluorescence analysis. Storage stability analyses were performed for a period of 21 days by monitoring the parameter $\mathrm{F}_{\mathrm{V}} / \mathrm{F}_{\mathrm{M}}$.

\subsection{Calibration curves and interference studies}

C. reinhardtii IL cultures in triplicates were incubated with $200 \mathrm{nM}$ nanoencapsulated atrazine for $24 \mathrm{~h}$ under continuous light $(50 \mu \mathrm{mol}$ photons $\mathrm{m}^{-2} \mathrm{~s}^{-1}$ ), at room temperature and continuous stirring (150 rpm). Control cultures were grown under physiological conditions and carried out in parallel in all trials. Photosynthetic activity of $C$. reinhardtii IL cell cultures were monitored according to the Section 2.3, performing a $15 \mathrm{~min}$ incubation with nanoencapsulated atrazine in a concentration range between 0.5 and $200 \mathrm{nM}$. Interference studies were performed after a $15 \mathrm{~min}$ incubation with solutions of $2 \mathrm{ppm}$ copper $\left(\mathrm{Cu}^{2+}\right), 10 \mathrm{ppb}$ arsenic (AsIII), and $100 \mathrm{nM}$ nanoencapsulated atrazine. Matrix effect was evaluated using a 1:2 dilution of tap water in Trisacetate-phosphate (TAP) medium $\mathrm{pH}$ 7.2.

\subsection{Statistical analyses}

Data from three separated experiments were analysed and mean values \pm standard deviation reported. For a given experiment, each condition was tested in triplicate. Detection limits were calculated on the basis of $99 \%$ confidence interval, which, assuming the normal distribution, corresponds to $2.6 \times$ standard error of the measurements $(\sigma)$, exploiting the modified relationship for the Langmuir absorption isotherm, $\mathrm{LOD}=2.6 \times \sigma \times \mathrm{I}_{20} /(100-2.6 \times \sigma)[30]$.

\section{Results and discussion}

Both empty poly( $\varepsilon$-caprolactone) nanocapsules and loaded with atrazine (nanoatrazine) have been previously characterized and showed similar results as stated in [25]. However, here, the physicochemical properties of both nanocapsules and nanocapsules loaded with atrazine (nanoatrazine) were determined and the results are showed in Fig. 1. Results obtained by DLS measurement (Fig. 1A) showed that the poly( $\varepsilon$ caprolactone) nanocapsules presented a mean size diameter of $250 \pm 2 \mathrm{~nm}$ e polydispersity index of $0.046 \pm 0.004$, while for nanoatrazine, the results showed a mean size diameter of $335 \pm 3 \mathrm{~nm}$ e polydispersity index of $0.157 \pm 0.09$. The zeta potential of nanocapsules and nanoatrazine showed a negative zeta potential of $-27 \mathrm{mV}$. The mean diameter was also measured by NTA (Fig. 1 B). For nanocapsules and nanoatrazine the mean size diameter and concentration of nanoparticles were $204 \pm 1 \mathrm{~nm}\left(1.23 \pm 0.06 \times 10^{13}\right.$ nanoparticles $/ \mathrm{mL})$ and $218 \pm 4 \mathrm{~nm}\left(1.17 \pm 0.05 \times 10^{13}\right.$ nanoparticles $/ \mathrm{mL}$ ) respectively. In addition, the micrographs of nanocapsules and nanoatrazine analysed by AFM are showed in Fig. 1C, D, respectively. According to these images, it can been seen that the nanoparticles showed a spherical shape. AFM images presented a narrow size distribution $(211 \pm 22 \mathrm{~nm}$ for nanocapsules and $270 \pm 13 \mathrm{~nm}$ for nanoatrazine), in agreement to the results obtained by DLS and NTA.

With the aim to characterise the physiological condition of the algae in the presence of both poly( $\varepsilon$-caprolactone) nanocapsules and nanoencapsulated-atrazine, their effect was investigated on algal growth, photosynthetic activity, and chlorophyll content. In this context, atrazine was exploited as reference herbicide to strength the validity of nanoencapsulated-atrazine analysis. Once optimised all the experimental conditions, algae were immobilised on a paper substrate soaked with an agar hydrogel to form a sort of thin film for algae absorption. The paper-based algal biosensor was challenged for nanoatrazine detection in both standard solutions and real samples. Also interference studies, matrix effect, recovery studies, and stability studies were optimised. In particular, the analytical performances of this device were evaluated in tap water, a vulnerable matrix of environmental and human health interest, which can be subject to pesticide pollution due to agricultural practices.

\subsection{Effect of nanoformulated herbicides on algae physiological parameters}

The physiological parameters of $C$. reinhardtii were evaluated in the presence of poly( $\varepsilon$-caprolactone) nanocapsules, nanoencapsulatedatrazine, and atrazine at a $200 \mathrm{nM}$ concentration, by following algae growth, photosynthetic activity, and chlorophyll content at specific incubation times.

In detail, cell number, chlorophyll $a$ fluorescence, and the total chlorophyll content were measured. Growth data indicated that PCL nanocapsules, nanoencapsulated-atrazine, and atrazine were not able to inhibit algal proliferation, indicating any influence on cell grow and emphasising any cytotoxic effects on $C$. reinhardtii algae in terms of altered vital processes and variations in the physiological parameters (e.g. cell duplication) (Fig. 2A).

The photochemical efficiency of PSII was evaluated by means of Kautsky curves as described in the Section 2.3 of "Methods", following both the maximum fluorescence yield of Photosystem II $\mathrm{F}_{\mathrm{V}} / \mathrm{F}_{\mathrm{M}}$ and the variable fluorescence parameter $1-\mathrm{V}_{\mathrm{J}}$ during an analysed period of $24 \mathrm{~h}$. In Fig. $2 \mathrm{~B}$ and $2 \mathrm{C}$, the fluorescence parameters $\mathrm{F}_{\mathrm{V}} / \mathrm{F}_{\mathrm{M}}$ and $1-\mathrm{V}_{\mathrm{J}}$ values were reported, calculated by each Kautsky curve, and plotted as function of time.

In particular, any effect was registered regarding the maximum fluorescence yield $\mathrm{F}_{\mathrm{V}} / \mathrm{F}_{\mathrm{M}}$ which remains constant during time, while the inhibitory effect of both nanoatrazine and atrazine was underlined by the decrease of the variable fluorescence $1-\mathrm{V}_{\mathrm{J}}$, being able to cause variations of the $\mathrm{F}_{\mathrm{V}}$ parameter (intimately connected with the $\mathrm{Q}_{\mathrm{A}}{ }^{-}$ accumulation). Results indicated that both herbicides were not able to completely block the photosynthetic activity of the algae, while affecting the transient changes in the redox state of the electron carriers within the PSII reaction centre, such as the accumulation of $Q_{A}$ in the reduced state and the further filling up of the membrane plastoquinone pool with electrons.

The content of photosynthetic total chlorophyll t (Chla and Chlb) also indicated any showed effect of PCL nanocapsules, nanoatrazine and atrazine, evidencing a similar pigment production profile after 4 and $24 \mathrm{~h}$ with respect to control cultures (Fig. 2D).

\subsection{Development of the paper-based algal biosensor}

\subsubsection{Immobilisation of $C$. reinhardtii on paper substrate}

C. reinhardtii whole-cells were immobilised on a paper substrate to provide a low-cost and sensitive analytical tool encompassing the fundamentals of sustainability proposed by the smart agriculture. Indeed, the combination of algae, recognised by the Food and Drug Administration (FDA) as a Generally Recognized as Safe (GRAS) organism [24], with an eco-friendly material, opens novel routes towards the basic principles of sustainability of the smart agriculture.

In detail, a $C$. reinhardtii cell culture in early mid-exponential growth phase, with $\mathrm{Abs}_{750} \sim 0.5$ O.D., corresponding to $(8 \pm 2) \times 10^{5}$ 
A

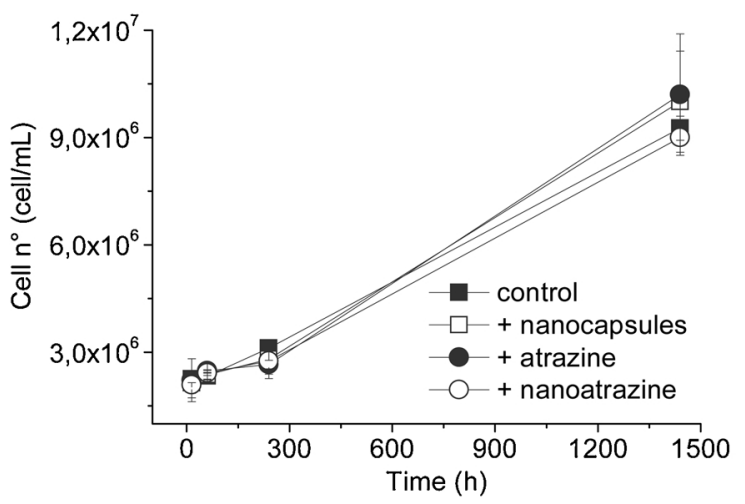

C

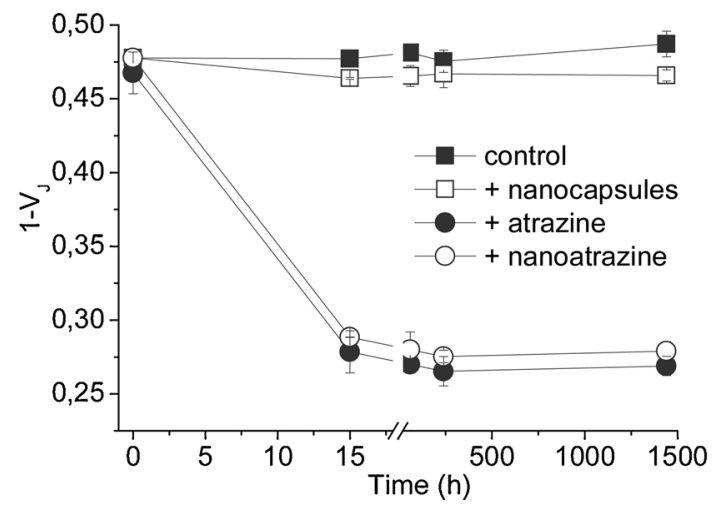

B

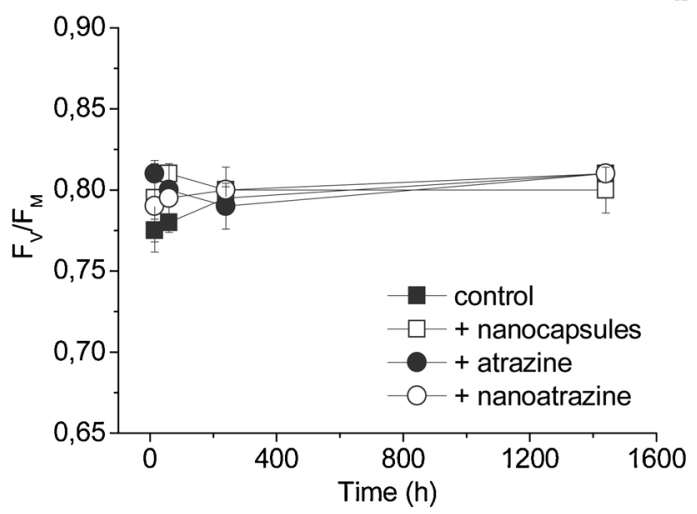

D

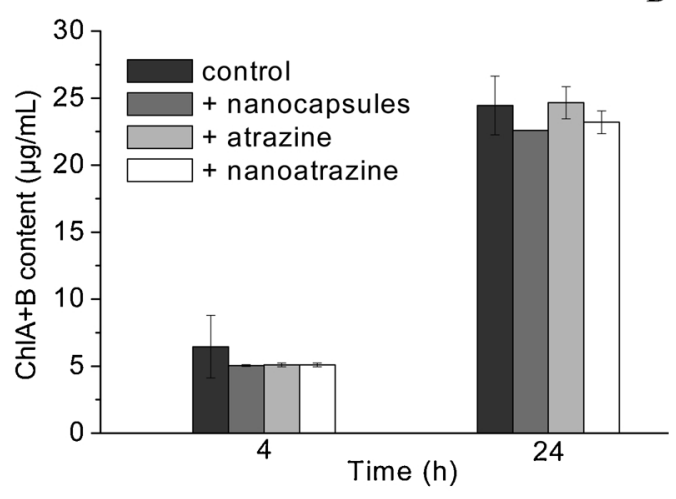

Fig. 2. C. reinhardtii physiological characterisation. Effect of $200 \mathrm{nM}$ atrazine and nanoencapsulated-atrazine on $C$. reinhardtii following: A) cell colture growth reported as cell number, B) maximum fluorescence yield $\mathrm{F}_{\mathrm{V}} / \mathrm{F}_{\mathrm{M}}$ calculated on each Kautsky curve, C) variable fluorescence 1- $\mathrm{V}_{\mathrm{J}}$ calculated on each Kautsky curve, and D) chlorophyll content. Incubation time: $24 \mathrm{~h}$ under continuous light $\left(50 \mu \mathrm{mol}\right.$ photons $\left.\mathrm{m}^{-2} \mathrm{~s}^{-1}\right)$. Average values $\pm \mathrm{SE}(\mathrm{n}=3)$.
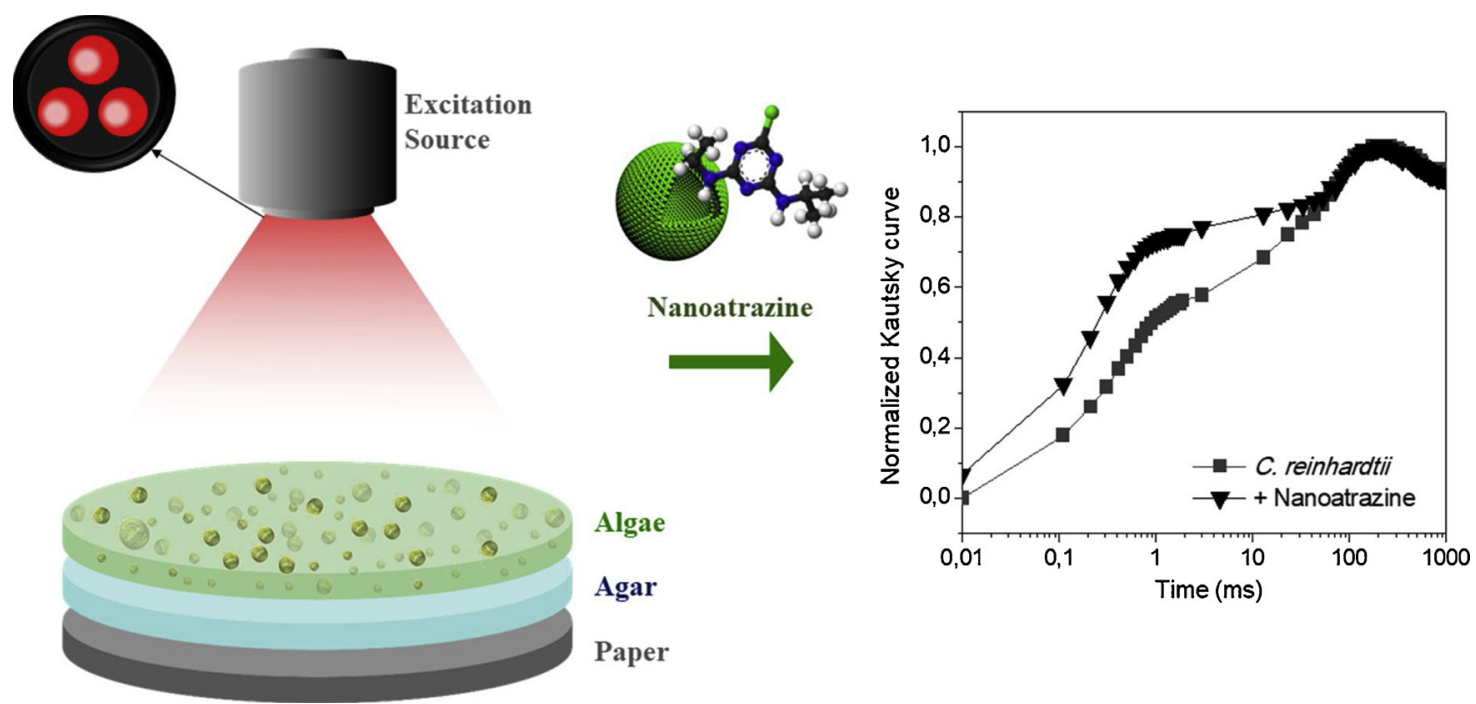

Fig. 3. Paper-based algal biosensor scheme. C. reinhardtii cells are immobilised on paper soaked into an agar hydrogel for the detection of nanoencapsulated-atrazine.

cells $/ \mathrm{ml}$ and $8 \mu \mathrm{g} / \mathrm{ml}$ chlorophyll content, was immobilised on a paper substrate (diameter $1 \mathrm{~cm}$ ) soaked into an $1.5 \%(\mathrm{w} / \mathrm{v})$ agar hydrogel made of Tris-acetate-phosphate (TAP) medium pH 7.2 to form a tin agar film for algae absorption. The paper substrate was then accommodated into a glass measurement cell of the PEA instrument for fluorescence analysis, with the aim to evaluate the bioreceptor response towards nanoatrazine by monitoring the variable fluorescence parameter $1-V_{J}$ calculated on the Kautsky curves, as well as its shelf lifetime by following the maximum fluorescence yield $\mathrm{F}_{\mathrm{V}} / \mathrm{F}_{\mathrm{M}}$. Fig. 3 reports a scheme of the proposed paper-based algal biosensor.

In order to better evaluate and deeply comprehend the accommodation of algae on the agar hydrogel/paper substrate, paper was observed at Scanning Electron Microscopy (SEM) before and after algae immobilisation. In particular, in Fig. 4 shows SEM microphotograph at a magnification of $20 \mu \mathrm{m}$ of i) paper substrate where paper fibres are visible (Fig. 4A), ii) paper soaked with the agar hydrogel showing how agar forms a tin film on paper fibres (Fig. 4B), and iii) agar hydrogel/ paper with immobilised algae highlighting the presence of algae cells 
A

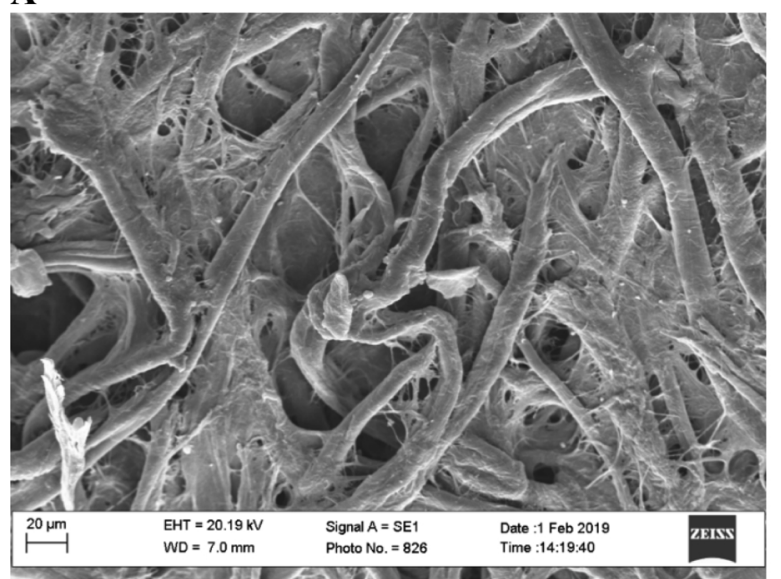

C

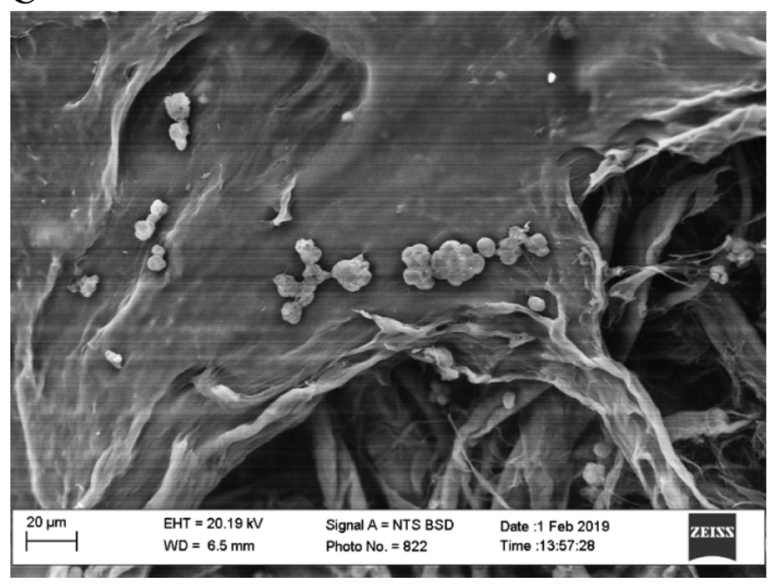

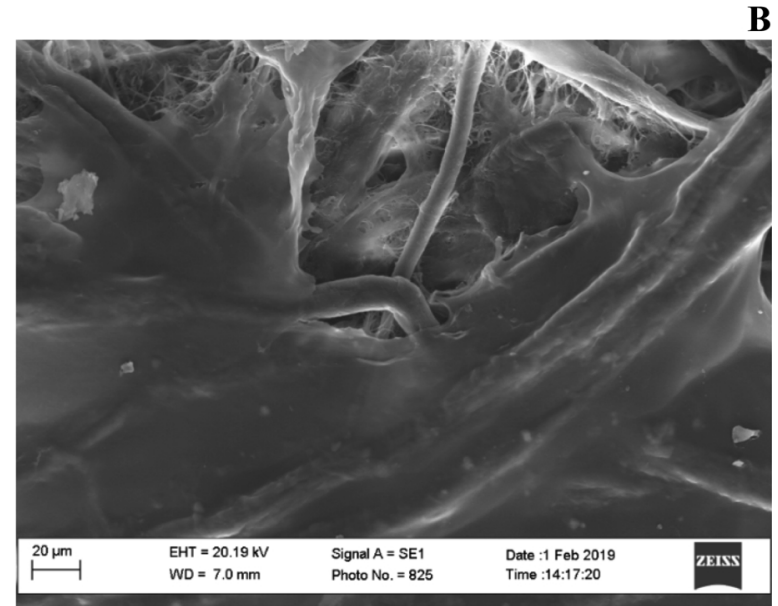

D

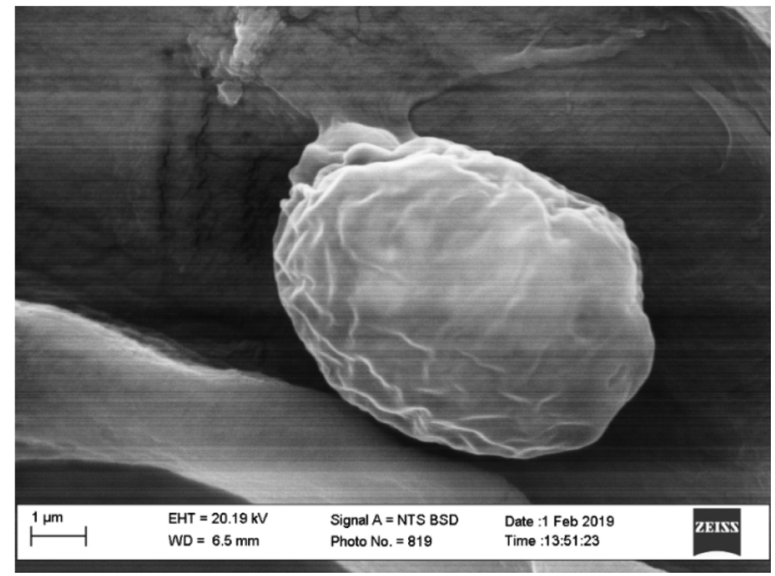

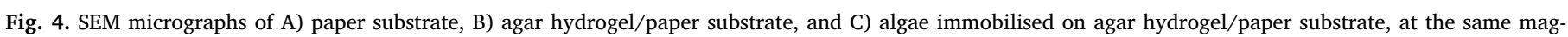
nification. D) Algae immobilised on agar hydrogel/paper substrate at a different magnification.

$\mathbf{A}$

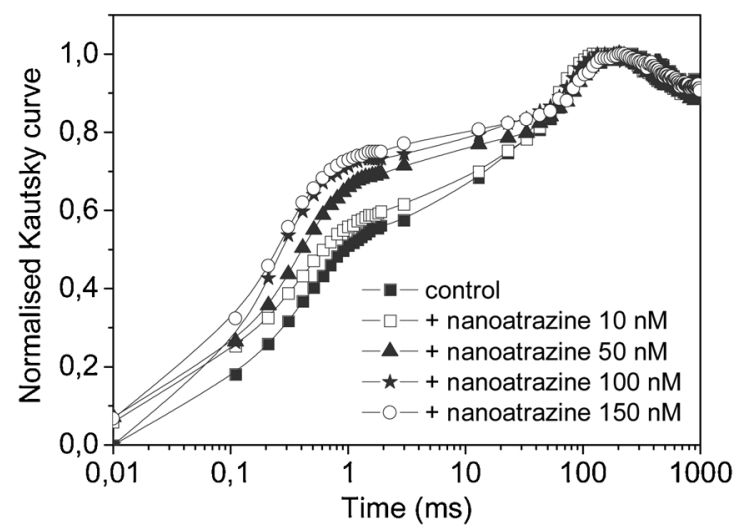

B

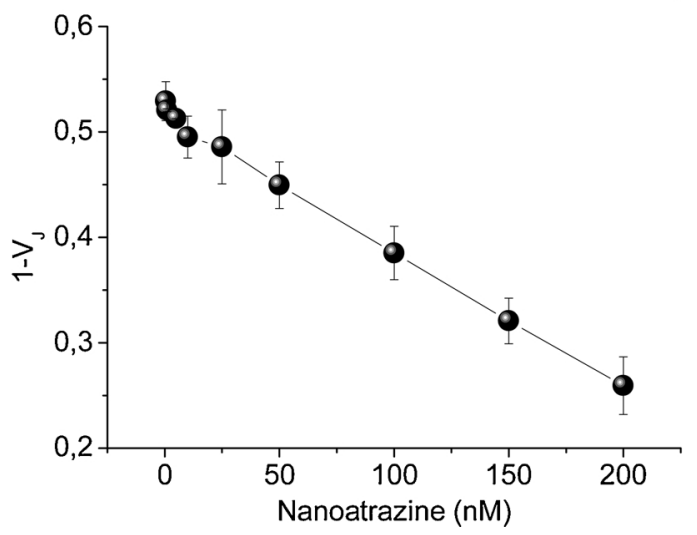

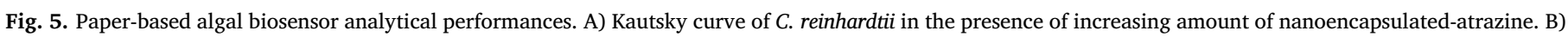
Variable fluorescence $1-\mathrm{V}_{\mathrm{J}}$ calculated on each curve (incubation time $15 \mathrm{~min}$ ). Average values $\pm \mathrm{SE}(\mathrm{n}=3$ ).

absorbed on the agar film (Fig. 4C). Fig. 4D shows algae immobilised on agar hydrogel/paper substrate at a magnification of $1 \mu \mathrm{m}$.

Beside the sustainability reason as above described, the main role of paper substrate was to fabricate an eco-friendly disposable dish where algae were absorbed and stored in a colture media-like environment retaining a good photosynthetic activity for up to 3 weeks. In case of herbicide analysis, the paper dish absorbed with algae was used as a disposable biosensor for the optical monitoring of nanoencapsulatedatrazine and further wasted as biodegradable material without impacting on the ecosystems. Moreover, the paper dish is a flexible support that can be easily customised and integrated in the measurement cell of the optical transduction system, thus allowing the construction of a reusable system where only the paper dish is wasted.

The so configured paper-based algal biosensor was challenged for nanoencapsulated-atrazine analysis in standard solutions and real samples. Also interference and recovery studies were performed, as described in the following sections. 
$\mathbf{A}$

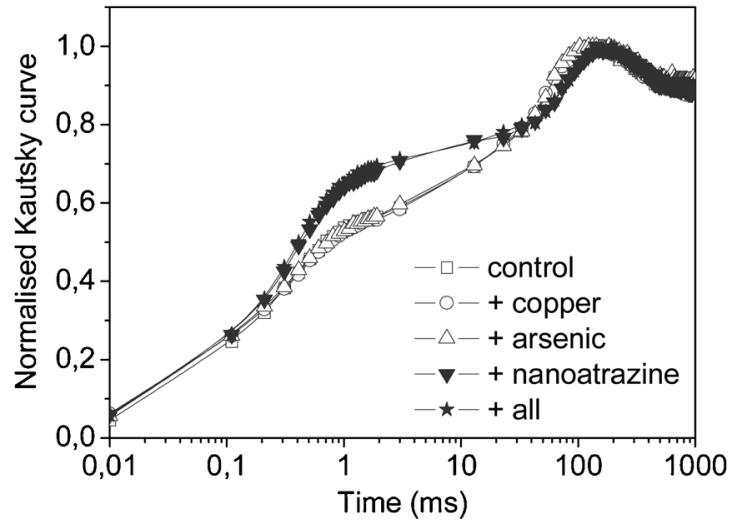

B

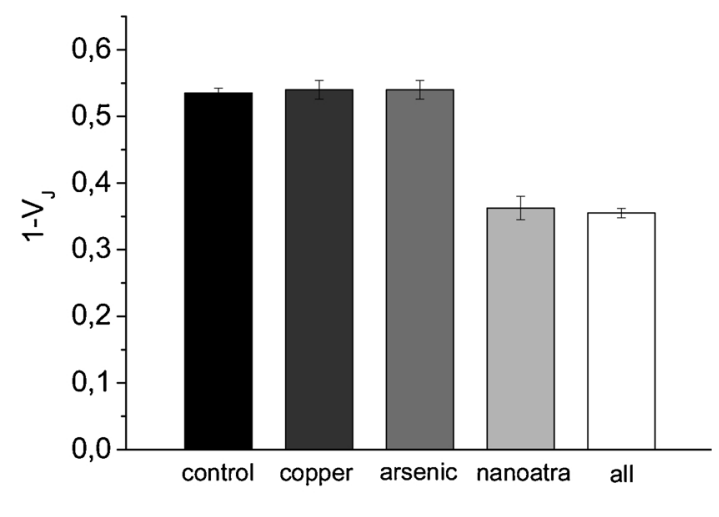

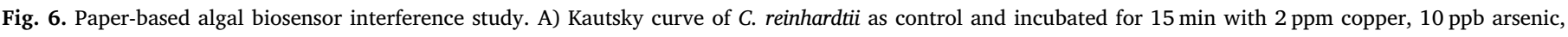

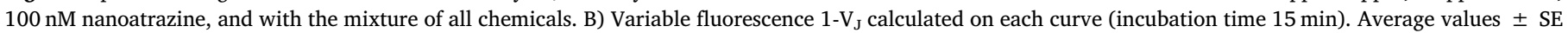
$(n=3)$.

$\mathbf{A}$

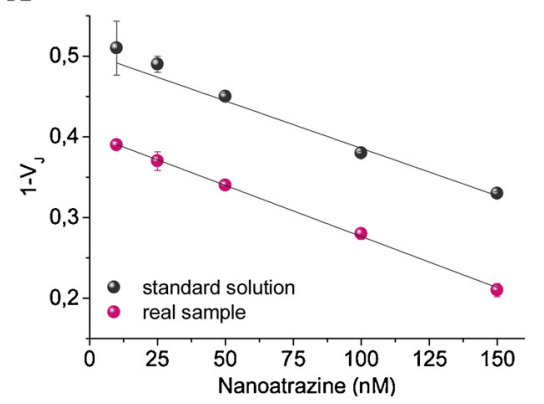

B

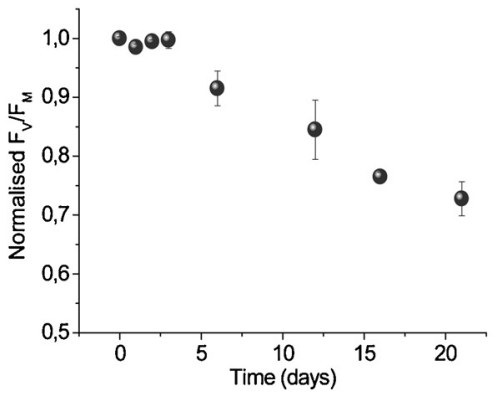

C

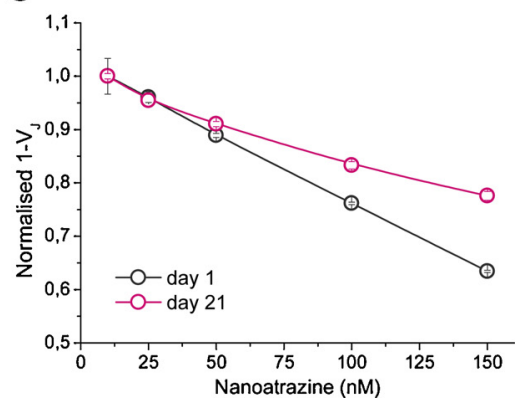

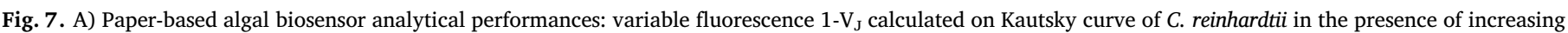

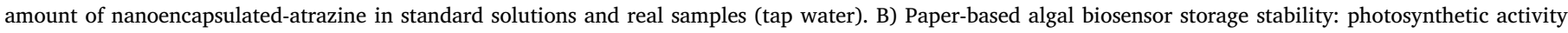

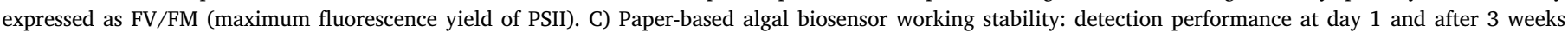
storage expressed as variable fluorescence parameter $1-V_{J}$ (incubation time $15 \mathrm{~min}, \mathrm{n}=3$ ).

Table 1

Recovery values for algae bioassay and paper algal biosensor from tap water $(n=3)$.

\begin{tabular}{llll}
\hline Sample & $\begin{array}{l}\text { Fortified nanoatrazine } \\
(\mathrm{nM})\end{array}$ & $\begin{array}{l}\text { Revealed nanoatrazine } \\
(\mathrm{nM})\end{array}$ & Recovery \% \\
\hline Tap water & 75 & $72 \pm 4$ & $96 \pm 5$ \\
\hline
\end{tabular}

3.2.2. Optimisation of nanoencapsulated-atrazine analysis in standard solutions

The paper-based algal biosensor was optimized for nanoencapsulated-atrazine detection by following the variable fluorescence parameter $1-\mathrm{V}_{\mathrm{J}}$ calculated from the algae fluorescence response described by the Kautsky curve. Thus, cell cultures at mid-point of exponential growth phase, entrapped in an agar hydrogel, and immobilised on paper were incubated for $15 \mathrm{~min}$ with standard solutions of nanoatrazine in a concentration range from 10 to $150 \mathrm{nM}$. Results evidenced that $1-V_{J}$ parameter decreased proportionally to the increase of nanoherbicide concentrations, allowing the construction of a calibration curve using the linear regression described by the equation $\mathrm{y}=0.503( \pm 0.005)-0.00117( \pm 0.00004) \mathrm{x}$, with an $\mathrm{R}^{2}=0.9809$. A detection limit of $4 \mathrm{pM}$ was obtained for $\mathrm{I}_{20}$ value (calculated as $2.6 \times \sigma$ $\times \mathrm{I}_{20} / 100-2.6 \times \sigma$ ). Fig. 5 reports the paper-based algal biosensor response towards nanoencapsulated-atrazine.

\subsubsection{Interference studies}

With the aim to challenge the capability of the proposed paperbased algal biosensor in drinking water samples, some chemicals including copper and arsenic were tested as interferences at legal level established by the EU Directive 98/83/EC for drinking water. In detail, C. reinhardtii was incubated for $15 \mathrm{~min}$ with standard solutions of $2 \mathrm{ppm}$ copper $\left(\mathrm{Cu}^{2+}\right), 10 \mathrm{ppb}$ arsenic (AsIII), and $100 \mathrm{nM}$ nanoencapsulatedatrazine as well as with a solution spiked with all the above listed compounds, to evaluate the synergistic effects of different chemicals in a mixture. Results reported in Fig. 6 highlighted that the interfering species did not affect the analysis of nanoencapsulated-atrazine at the exploited concentrations.

\subsubsection{Matrix effect, recovery, and stability studies}

To investigate the suitability of the proposed paper-based algal biosensor in real samples, matrix effect and recovery studies were performed. To estimate matrix effect, a $C$. reinhardtii cell culture was diluted 1:2 (v:v) in tap water fortified with nanoencapsulated-atrazine in a concentration range from 10 and $150 \mu \mathrm{M}$. The conditions of the cell cultures resulting from the dilution were in agreement with the optimised conditions set up for all the previous experimental sessions (Section 2.3 of Methods). A calibration curve was constructed calculating the $1-\mathrm{V}_{\mathrm{J}}$ parameter (Fig. $7 \mathrm{~A}$ ), obtaining a linear range of detection in the $10-150 \mathrm{nM}$ range, described by the equation $\mathrm{y}=0.403( \pm 0.004)-0.00127( \pm 0.00006) \times\left(\mathrm{R}^{2}=0.999\right)$. A detection limit of $4 \mathrm{pM}$ (calculated as $2.6 \times \sigma \times \mathrm{I}_{20} /(100-2.6 \times \sigma)$ ) was assessed. The slopes of the calibration curves obtained in standard solutions and real samples were very similar with a ratios of 1.08 , indicating a very slightly dependence from the tap water matrix. The calibration curve obtained for the paper-based algal biosensor challenged in real samples was further used to calculate the recovery values 


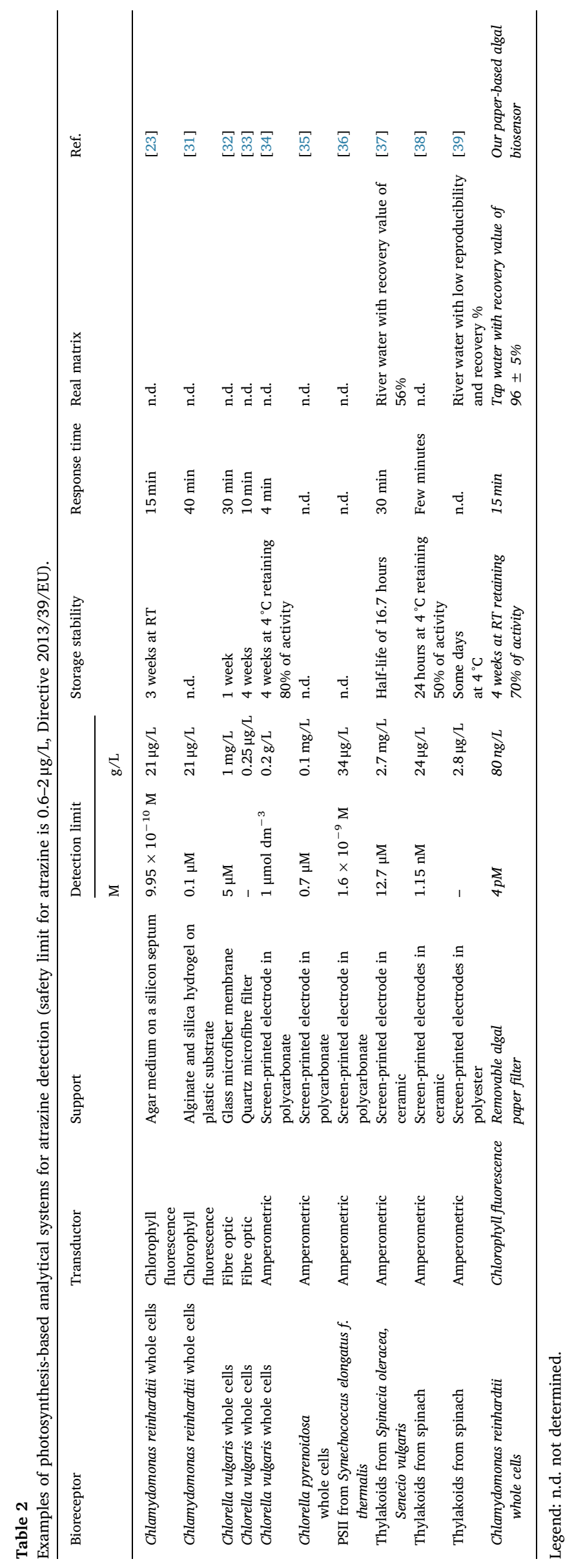


of the tap water samples. A recovery value of $96 \pm 5 \%$ was obtained for $75 \mathrm{nM}$ of nanoencapsulated-atrazine, highlighting a satisfactory capability to detect nanoatrazine also in real samples (Table 1).

The shelf life time of the paper-based algal biosensor was also evaluated by storing algae immobilised on the paper substrate and located in the glass measurement cell under continuous light $(50 \mu \mathrm{mol}$ photons $\mathrm{m}^{-2} \mathrm{~s}^{-1}$ ) at RT for 1 month. Assessing the photosynthetic activity expressed as $\mathrm{F}_{\mathrm{V}} / \mathrm{F}_{\mathrm{M}}$ (maximum fluorescence yield of PSII), the paper-based algal biosensor was able to retain a good photosynthetic activity (70\% activity) for up to 3 weeks (Fig. 7B). Moreover, the working stability of the paper-based algal biosensor was also tested evaluating its capability to detect nanoencapsulated-atrazine after a period of 3 weeks, by the variable fluorescence parameter $1-V_{J}$. The results reported in Fig. $7 \mathrm{C}$ highlighted that after 21 days of storage at RT and under continuous light $\left(50 \mu \mathrm{mol}\right.$ photons $\left.\mathrm{m}^{-2} \mathrm{~s}^{-1}\right)$, the biosensor lost its capability toward nanoatrazine detection by a factor of $15 \%$.

The proposed paper-based algal biosensor demonstrated to be able of revealing nanoencapsulated-atrazine with detection limit in the picomolar range ( $4 \mathrm{pM}$ corresponding to $80 \mathrm{ng} / \mathrm{L}$ ), meeting the requirements of atrazine law limits between 0.6 and $2 \mu \mathrm{g} / \mathrm{L}$ (Directive 2013/ $39 / \mathrm{EU}$ ) [9]. The biosensor was also challenged in tap water, a vulnerable matrix that can be subject to pesticide pollution due to agricultural practices, indicating its suitability for herbicide analysis in real samples and without interferences from compounds which can be present at safety limits provided by the EU Directive 98/83/EC for drinking water as well as with very slight matrix effect and satisfactory recovery values. In addition, being this biosensor based on a whole-cell bioreceptor, no sample pre-treatment was required. The biosensor is also capable to meet the requirements of sustainability, being a totally ecodesigned device composed of biodegradable materials (both bioreceptor and substrate) without impacting on the environment. Moreover, it represents a simple and cost-effective analytical tool for application in smart agriculture where the use of novel nanoformulations (e.g. fertilisers/pesticides encapsulated on nano-delivery systems) is gaining momentum and against whom novel implements need to be further developed.

Furthermore, taking into account these promising results, the proposed biosensor represents a competitive tool towards similar photosynthesis-based analytical systems reported in literature, owing to its very high sensitivity and stability, as well as its eco-designed configuration. Some of the most representative examples are summarized in Table 2, based on different sources of photosynthetic elements including whole cells, thylakoids and PSII particles from different photosynthetic organisms, as well as different transductors as optical and electrochemical ones

\section{Acknowledgements}

This work was supported by NanoSWS project EraNetMed - RQ32016. L.F.F and E.V.R.C would like to thank São Paulo Science Foundation (FAPESP). Authors express gratitude to the staff of the Institute of Crystallography (National Research Council) in the person of Loredana Caccavale for her precious help performing laboratory experiments with photosynthetic microalgae. Authors express gratitude also to Ing. Francesco Gallucci (CRA-ING, CREA, Consiglio Ricerca Agricoltura e Analisi Economia Agraria) for his precious support in SEM analysis.

\section{References}

[1] A. Antonacci, F. Arduini, D. Moscone, G. Palleschi, V. Scognamiglio, Nanostructured (Bio) Sensors For Smart Agriculture, TrAC. 98 (2017) 95-103, https://doi.org/10.1016/j.trac.2017.10.022.

[2] V. Scognamiglio, G. Rea, F. Arduini, G. Palleschi, $1^{\text {st }}$ ed, Biosensors for Sustainable Food-New Opportunities and Technical Challenges vol. 74, Elsevier, 2016.

[3] L.F. Fraceto, R. Grillo, G.A. de Medeiros, V. Scognamiglio, G. Rea, C. Bartolucci, Nanotechnology in agriculture: which innovation potential does it have? Front
Environ. Sci. 4 (2016) 20-25, https://doi.org/10.3389/fenvs.2016.00020.

4] J. Jampílek, K. Králová, Nanopesticides: preparation, targeting, and controlled release, in: A.M. Grumezescu (Ed.), New Pesticides and Soil Sensors, Academic Pres, 2017, pp. 81-127.

[5] M. Kah, P. Machinski, P. Koerner, K. Tiede, R. Grillo, L.F. Fraceto, T. Hofmann, Analysing the fate of nanopesticides in soil and the applicability of regulatory protocols using a polymer-based nanoformulation of atrazine, Environ. Sci. Pollut. Res. Int. 21 (2014) 11699-11707, https://doi.org/10.1007/s11356-014-2523-6.

[6] A. Domínguez-Garay, K. Boltes, A. Esteve-Núñez, Cleaning-up atrazine polluted soil by using microbial electroremediating cells, Chemosphere. 161 (2016) 365-371 https://doi.org/10.1016/j.chemosphere.2016.07.023.

[7] X. Kong, J. Jiang, J. Ma, Y. Yang, W. Liu, Y. Liu, Degradation of atrazine by UV/ chlorine: efficiency, influencing factors, and products, Water Res. 90 (2016) 15-23, https://doi.org/10.1016/j.watres.2015.11.068.

[8] W. Ouyang, X. Zhao, M. Tysklind, F. Hao, Typical agricultural diffuse herbicide sorption with agricultural waste-derived biochars amended soil of high organic matter content, Water Res. 92 (2016) 156-163, https://doi.org/10.1016/j.watres. 2016.01.055.

[9] Directive, (2013) /39/EU https://eur-lex.europa.eu/LexUriServ/LexUriServ.do? uri $=$ OJ:L:2013:226:0001:0017:EN:PDF

[10] H.C. Oliveira, R. Stolf-Moreira, C.B.R. Martinez, R. Grillo, M.B. de Jesus, L.F. Fraceto, Nanoencapsulation enhances the post-emergence herbicidal activity of atrazine against mustard plants, PLoS One 10 (7) (2015) e0132971, , https://doi. org/10.1371/journal.pone.0132971.

[11] J. Chang, H. Li, T. Hou, F. Li, Paper-based fluorescent sensor for rapid naked-eye detection of acetylcholinesterase activity and organophosphorus pesticides with high sensitivity and selectivity, Biosens. Bioelectron. 86 (2016) 971-977, https:// doi.org/10.1016/j.bios.2016.07.022.

[12] T. Soga, Y. Jimbo, K. Suzuki, D. Citterio, Inkjet-printed paper-based colorimetric sensor array for the discrimination of volatile primary amines, Anal. Chem. 85 (19) (2013) 8973-8978, https://doi.org/10.1021/ac402070z.

[13] P.V.L. Reddy, K.H. Kim, A review of photochemical approaches for the treatment of a wide range of pesticides, J. Hazard. Mater. 285 (2015) 325-335, https://doi.org/ 10.1016/j.jhazmat.2014.11.036.

[14] C. Wang, X. Wang, P. Gai, H. Li, F. Li, Target-responsive AIE-Au nanoconjugate for acetylcholinesterase activity and inhibitor assay with ultralow background noise, Sens. Actuators B Chem. 284 (2019) 118-124, https://doi.org/10.1016/j.snb.2018. 12.107.

[15] F. Arduini, S. Cinti, V. Caratelli, L. Amendola, G. Palleschi, D. Moscone, Origam multiple paper-based electrochemical biosensors for pesticide detection, Biosens. Bioelectron. 126 (2019) 346-354, https://doi.org/10.1016/j.bios.2018.10.014.

[16] N. Colozza, K. Kehe, G. Dionisi, T. Popp, A. Tsoutsoulopoulos, D. Steinritz, F. Moscone, Arduini, A wearable origami-like paper-based electrochemical biosensor for sulfur mustard detection, Biosens. Bioelectron. 129 (2019) 15-23, https://doi.org/10.1016/j.bios.2019.01.002.

[17] F. Arduini, S. Cinti, V.D. Scognamiglio, Moscone, past, present and future challenges of biosensors and bioanalytical tools in: analytical chemistry: a tribute to Professor Marco Mascini, Compr. Anal. Chem. (2017) 385.

[18] F. Arduini, S. Cinti, V. Scognamiglio, D. Moscone, G. Palleschi, How cutting-edge technologies impact the design of electrochemical (bio) sensors for environmental analysis. A review, Anal. Chim. Acta 959 (2017) 15-42, https://doi.org/10.1016/j. aca.2016.12.035.

[19] S. Boisvert, D. Joly, R. Carpentier, Quantitative analysis of the experimental O-J-I-P chlorophyll fluorescence induction kinetics, FEBS J. 273 (2006) 4770-4777, https://doi.org/10.1111/j.1742-4658.2006.05475.x.

[20] A. Stirbet, On the relation between the Kautsky effect (chlorophyll a fluorescence induction) and photosystem II: basics and applications of the OJIP fluorescence transient, J. Photochem. Photobiol. B, Biol. 104 (2011) 236-257, https://doi.org/ 10.1016/j.jphotobiol.2010.12.010.

[21] A. Stirbet, B.J. Strasser, R.J. Strasser, ChlorophyllaFluorescence Induction in Higher Plants: Modelling and Numerical Simulation, J. Theor. Biol. 193 (1998) 131-151, https://doi.org/10.1006/jtbi.1998.0692.

[22] R.J. Strasser, A. Srivastava, M. Tsimilli-Michael, Yhe fluorescence transient as a tool to characterize and screen photosynthetic samples, in: M. Yunus, U. Pathre, P. Mohanty (Eds.), Probing Photosynthesis: Mechanisms, Regulation and Adaptation, Taylor \& Francis, London, UK, 2000, pp. 445-483.

[23] V. Scognamiglio, D. Raffi, M. Lambreva, G. Rea, A. Tibuzzi, G. Pezzotti, U. Johanningmeier, M.T. Giardi, Chlamydomonas reinhardtii genetic variants as probes for fluorescence sensing system in detection of pollutants, Anal. Bioanal. Chem. 394 (2009) 1081, https://doi.org/10.1007/s00216-009-2668-1.

[24] Sections 201/409 of Federal Food, Drug, and Cosmetic Act, (2018) https://www. fda.gov/Food/IngredientsPackagingLabeling/GRAS/.

[25] R. Grillo, N.Z.P. dos Santos, C.R. Maruyama, A.H. Rosa, de Lima R, L.F. Fraceto, Poly ( $\varepsilon$-caprolactone) nanocapsules as carrier systems for herbicides: Physico-chemical characterization and genotoxicity evaluation, J. Hazard. Mater. 231 (2012) 1, https://doi.org/10.1016/j.jhazmat.2012.06.019.

[26] G. Rea, M. Lambreva, F. Polticelli, I. Bertalan, A. Antonacci, S. Pastorelli, M. Damasso, U. Johanningmeier, M.T. Giardi, Directed evolution and in silico analysis of reaction centre proteins reveal molecular signatures of photosynthesis adaptation to radiation pressure, PLoS One 6 (1) (2011) e16216, , https://doi.org/ 10.1371/journal.pone.0016216.

[27] U. Johanningmeier, S. Heiss, Construction of a Chlamydomonas reinhardtii mutant with an intronless psbA gene, Plant Mol. Biol. 22 (1993) 91-99, https://doi.org/10. 1007/BF00038998.

[28] J.K. Hoober, The Chlamydomonas sourcebook: a comprehensive guide to biology and laboratory use, Science 246 (1989) 1503-1504. 
[29] H.K. Lichtenthaler, A.R. Wellburn, Degradation of atrazine by UV/chlorine: efficiency, influencing factors, and products, Biochem. Soc. Trans. 11 (1983) 591-592, https://doi.org/10.1016/j.watres.2015.11.068.

[30] M. Koblížek, J. Malý, J. Masojídek, J. Komenda, T. Kučera, M.T. Giardi, A.K. Mattoo, R. Pilloton, A biosensor for the detection of triazine and phenylurea herbicides designed using Photosystem II coupled to a screen-printed electrode, Biotechnol. Bioeng. 78 (2002) 110-116, https://doi.org/10.1002/bit.10190.

[31] Y. Ferro, M. Perullini, M. Jobbagy, S.A. Bilmes, C. Durrieu, Development of a biosensor for environmental monitoring based on microalgae immobilized in silica hydrogels, Sensors 12 (2012) 16879-16891, https://doi.org/10.3390/s121216879.

[32] M. Naessens, J.C. Leclerc, C. Tran-Minh, Fiber optic biosensor using Chlorella vulgaris for determination of toxic compounds, Ecotoxicol. Environ. Saf. 46 (2000) 181-185, https://doi.org/10.1006/eesa.1999.1904.

[33] C. Védrine, J.C. Leclerc, C. Durrieu, C. Tran-Minh, Optical whole-cell biosensor using Chlorella vulgaris designed for monitoring herbicides, Biosens. Bioelectron. 18 (2003) 457-463, https://doi.org/10.1016/S0956-5663(02)00157-4.

[34] I. Shitanda, S. Takamatsu, K. Watanabe, M. Itagaki, Amperometric screen-printed algal biosensor with flow injection analysis system for detection of environmental toxic compounds, Electrochim. Acta 54 (2009) 4933-4936, https://doi.org/10. 1016/j.electacta.2009.04.005.

[35] A.I. Zamaleeva, I.R. Sharipova, R.V. Shamagsumova, A.N. Ivanov, G.A. Evtugyn, D.G. Ishmuchametova, R.F. Fakhrullin, A whole-cell amperometric herbicide biosensor based on magnetically functionalised microalgae and screen-printed electrodes, Anal. Methods 3 (2011) 509-513, https://doi.org/10.1039/C0AY00627K.

[36] J. Masojídek, P. Souček, J. Máchová, J. Frolík, K. Klem, J. Malý, Detection of photosynthetic herbicides: Algal growth inhibition test vs. electrochemical photosystem II biosensor, Ecotoxicol. Environ. Saf. 74 (2011) 117-122, https://doi.org/ 10.1016/j.ecoenv.2010.08.028.

[37] E. Touloupakis, L. Giannoudi, S.A. Piletsky, L. Guzzella, F. Pozzoni, M.T. Giardi, A multi-biosensor based on immobilized Photosystem II on screen-printed electrodes for the detection of herbicides in river water, Biosens. Bioelectron. 20 (2005) 1984-1992, https://doi.org/10.1016/j.bios.2004.08.035.

[38] V. Bhalla, X. Zhao, V. Zazubovich, Detection of explosive compounds using Photosystem II-based biosensor, J. Electroanal. Chem. 657 (2011) 84-90, https:// doi.org/10.1016/j.jelechem.2011.03.026.

[39] F. Bettazzi, S. Laschi, M. Mascini, One-shot screen-printed thylakoid membranebased biosensor for the detection of photosynthetic inhibitors in discrete samples, Anal. Chim. Acta 589 (2007) 14-21, https://doi.org/10.1016/j.aca.2007.02.062. 